\title{
STUDY OF INDUCTION GENERATORS PERFORMANCE OF TWO-SPEED USED IN STANDALONE WIND TURBINES
}

\author{
Omran Al-abed Al-khamis ${ }^{1}$ \\ Abdulmotaleb abu safe ${ }^{2}$ \\ ${ }^{1}$ Dicle University Engineering Faculty Department of Electrical \& Electronic Engineering, Turkey. \\ ${ }^{2}$ Damascus University, Faculty of Mechanical \& Electrical Engineering, Department of Electrical \\ Engineering, Syria.
}

\begin{abstract}
Recent interest in renewable energy sources is growing as a resource substitute for conventional energy and this led to increased interest in electric power can be obtained from the wind energy.

With the rapid development in electrical generators used in wind turbines, induction generators have proven quality among the different types of electric generators used in this field.

Based on that research aims to study the behavior of squirrel cage induction generator(two-speed) when linked with a wind turbine and study of using feasibility in this field.

To achieve this purpose theoretical and practical study for induction generator two- speed were completed.

Theoretical study contains a review of principles of operation of the machine, circuit equivalent and math equations, but practical study has been fulfilled on a laboratory model for two-speed induction generator driven by DC motor with variable speed.

This study has been fulfilled when induction generator operates on both of speed and set speed at which it move from working as a motor to work as a generator for different values of the excitation capacitors, and relationship between voltage of generator and speed is identified at different degrees of excitation.
\end{abstract}

KEY WORDS: Induction Generator, Self-Excitation, Reactive Power, Wind Energy.

\section{INTRODUCTION}

In this days, the issue of renewable sources for electric power is getting attention, because of increasing of conventional energy problems such as environmental pollution[10].

Wind energy considers the most renewable energy sources that is depend on the future. 
Electrical power which can be obtained from wind turbines relates to wind speeds sharply (speed and power linked to the equation of the third degree)[10];so, there is difficulty in extracting the maximum possible power from the wind and convert it into electrical energy by electric generators.

feasibility of converting wind energy into electrical energy relates to specifications and type of electrical generator that linked with wind turbine.

The three-phase induction generator is the best types of generators for using with wind turbines to generate electricity,[13] thanks to the positive advantages, which are commensurate with work in wind turbine.

The most important advantages in induction generators are simple structure, high Reliability, high efficiency, and ability to work on the changing speed of the wind turbine [8][12][14].

In order to increase the feasibility of using these machines with wind turbines, we are resorting to use different types from driving and control circuits even get the required quality of electric power (nominal values of voltage and frequency) at the highest possible values for efficiency.

However, driving and control circuits lead in many cases to complexity of the structure of wind generation groups and reduce the degree of reliability, increase constituent cost, increase the cost of the necessary maintenance.

Therefore, the looking for a simpler structure for group of wind generation that achieves the possibility of benefiting from wind energy converted to electrical energy is great importance.

Induction Generators (two-speed) provide a good possibility to achieve this goal as it allows the exploitation of wind energy at two different of speed using a single machine without the need for additional expensive equipment.

\section{INDUCTION GENERATOR-PRINCIPLE OF OPERATION-EQUIVALENT CIRCUIT}

The induction machine is a reversible machine, being able to work as a motor and as a generator alike.

As we mentioned earlier induction machines use widely as generators of electric power when operates with wind turbines thanks to advantages.

In order to work the induction machine as a generator connected to the grid, is applied on its stator winding the nominal voltage and the rotor is rotated by a prime mover in speed $n$ that is higher than the synchronous speed $n_{1}$ and in the same direction of rotation of the magnetic flux,[13] then slip $s=\frac{n_{1}-n}{n_{1}}$ becomes a negative [5][7].

From the equivalent electrical circuit for induction motor (figure1) rotor current equals :

$$
\begin{aligned}
\overline{I_{2}^{\prime}} & =\frac{\overline{E_{2 s}^{\prime}}}{R_{2}^{\prime}+j s X_{2}^{\prime}}=\frac{s \cdot \overline{E_{2}^{\prime}}}{R_{2}^{\prime}+j s \cdot X_{2}^{\prime}} \cdot \frac{R_{2}^{\prime}-j s X_{2}^{\prime}}{R_{2}^{\prime}-j s X_{2}^{\prime}}= \\
& =\overline{E_{2}^{\prime}}\left[\frac{s \cdot R_{2}^{\prime}}{R_{2}^{\prime 2}+s^{2} X_{2}^{\prime 2}}-j \frac{s^{2} X_{2}^{\prime 2}}{R_{2}^{\prime 2}+s^{2} X_{2}^{\prime 2}}\right]=I_{2 a}^{\prime}-j I_{2 r}^{\prime}
\end{aligned}
$$


When the induction machine operates as a motor slip will be Positive $(s>0)$, current $I_{2}$ (real part of current $I_{2 a}^{\prime}$ and imagine part of current $I_{2 r}^{\prime}$ ) will be Positive , $I_{2 r}^{\prime}$ is lagging from $I_{2 a}^{\prime}$ by $90^{\circ}$.

For obtaining the vector of stator current $I_{1}$, we add vector of magnetized current $I_{O}$ to vector of rotor current $I_{2}$ :

$$
\begin{gathered}
\overline{I_{1}}=\bar{I}_{O}+\overline{I_{2}} \\
\bar{I}_{O}=\overline{E_{2 S}^{\prime}} \times\left(G_{o}-j B_{o}\right)
\end{gathered}
$$

the two part of current $I_{1}$ are positive in another meaning:

$$
\begin{aligned}
& I_{1 a}=I_{1} \cos \varphi_{1}>0 \\
& I_{1 r}=I_{1} \sin \varphi_{1}>0
\end{aligned}
$$

Where $: \varphi_{1}$ :The phase angle between the current $I_{1}$ and the voltage $U_{1}$.

then all of the active and reactive power are positive:

$$
\begin{aligned}
& P_{1}=m_{1} U_{1} I_{1} \cos \varphi_{1}>0 \\
& Q_{1}=m_{1} U_{1} I_{1} \sin \varphi_{1}>0
\end{aligned}
$$

This means that the motor draws active and reactive power from network.

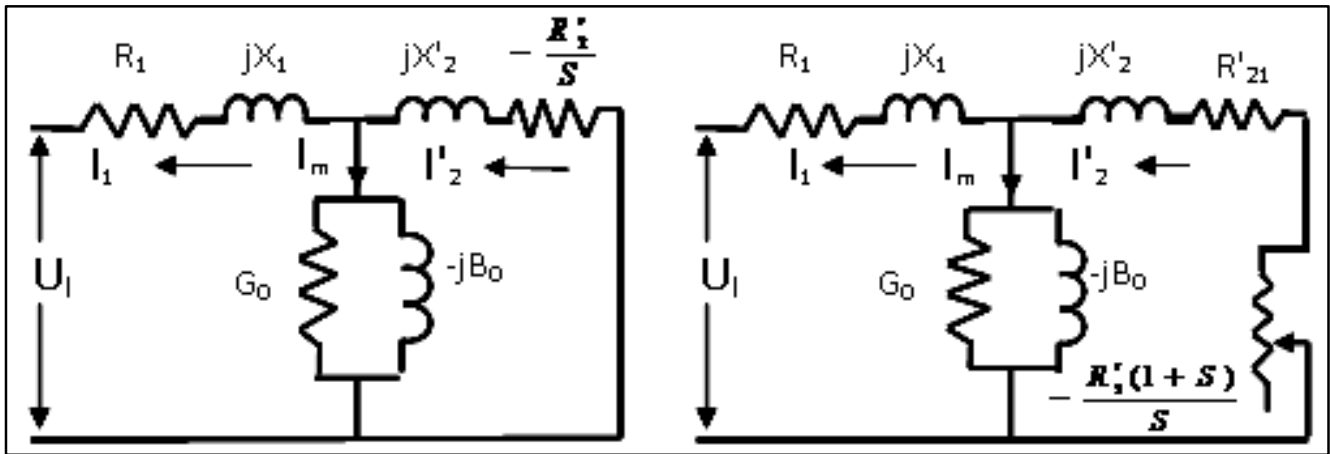

Figure 1. Equivalent Circuit for Induction Generator[3].

But when the slip is negative, the imagine part of current $I_{2 r}^{\prime}$ remains positive, while real part of current $I_{2 a}^{\prime}$ changes its signal and become negative, in another meaning the phase angle will change $180^{\circ}$, the signal of $E_{2 S}^{\prime}$ will change too, the current vector $I_{1}$ is reflected by almost $180^{\circ}$, then $\varphi_{1}>$ $90^{\circ}$ as shown in figure (2) then:

$$
\begin{gathered}
P_{1}=m_{1} U_{1} I_{1} \cos \varphi_{1}<0 \\
I_{1 a}=I_{1} \cos \varphi_{1}<0
\end{gathered}
$$

That is the real part of the current $I_{1}$ and active power $P_{1}$ alters their signals and then the machine does not draw active power from grid, but the machine provides active power to grid, this means that the machine becomes operates as a generator, and converts mechanical power into electrical power . 


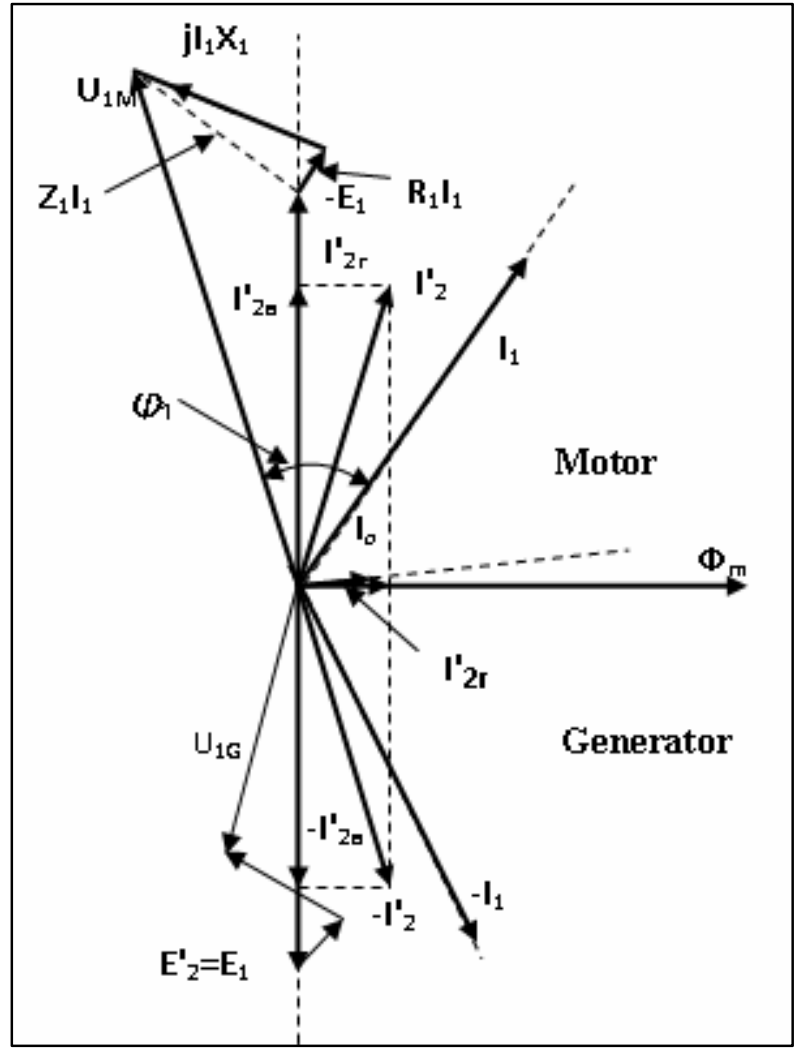

Figure 2. Vector Diagram for Voltages \& Currents in Induction Motor \& Generator[1].

We also note the equation (1) that the imagine current $I_{2 r}^{\prime}$ remains positive when slip $s$ is negative, when operates the machine as a generator, and then values,

$$
\begin{aligned}
Q_{1} & =m_{1} U_{1} I_{1} \sin \varphi_{1} \\
I_{1 r} & =I_{1} \sin \varphi_{1}
\end{aligned}
$$

maintain on their signals, and this means that the induction machine (when operates as a generator) is drawing from the grid magnetization current and reactive power; so it cannot operates as a generator unless connected in parallel with the source that feeds it by magnetization current and reactive power which necessary for producing magnetic flux or can link capacitors in parallel to supply it by reactive power [10][11][13].

Magnetization current value in induction machine can be reach to $(25-50) \%$ from the nominal current when it operates with no load; so we must secure the magnetization power required for producing this current in addition to reactive power that required for load which connected to the machine [1][14].

\subsection{SELF-EXCITATION INDUCTION GENERATOR}

In order to operate the induction generator independent of the electrical grid, uses a three phase capacitors that connected star or delta as the source of reactive power that needed to excite the 
machine, where the capacitors are linked with stator in parallel to supply the generator in magnetization current that needed to generate magnetic flux, and called the generator in this case by a self-excitation induction generator figure (3) shows the electrical circuit for self-excitation induction generator [6][11].

Self-excitation process starts in induction generator depending on the residual magnetic flux in iron core, induction machine's core ,after separated from the excitation source stores residual magnetic flux $\varphi_{\text {rem }}$, when the rotor rotates in speed $n$ higher than the synchronous speed $n_{1}$, in stator winding will induce small electromotive force $E_{\text {rem }}$ due to the small value of the residual magnetic flux which generated it,[8][14] electromotive force generates capacitive current :

$$
\dot{I}_{C}=\frac{E}{X_{C}}=\omega_{1} C E
$$

that passes in capacitors circuit which linked with stator winding, value of this current relates to leakage reactance for winding, and capacitive reactance $X_{C}$ for capacitors, $I_{C}=\frac{E}{X_{1}+X_{O}}$

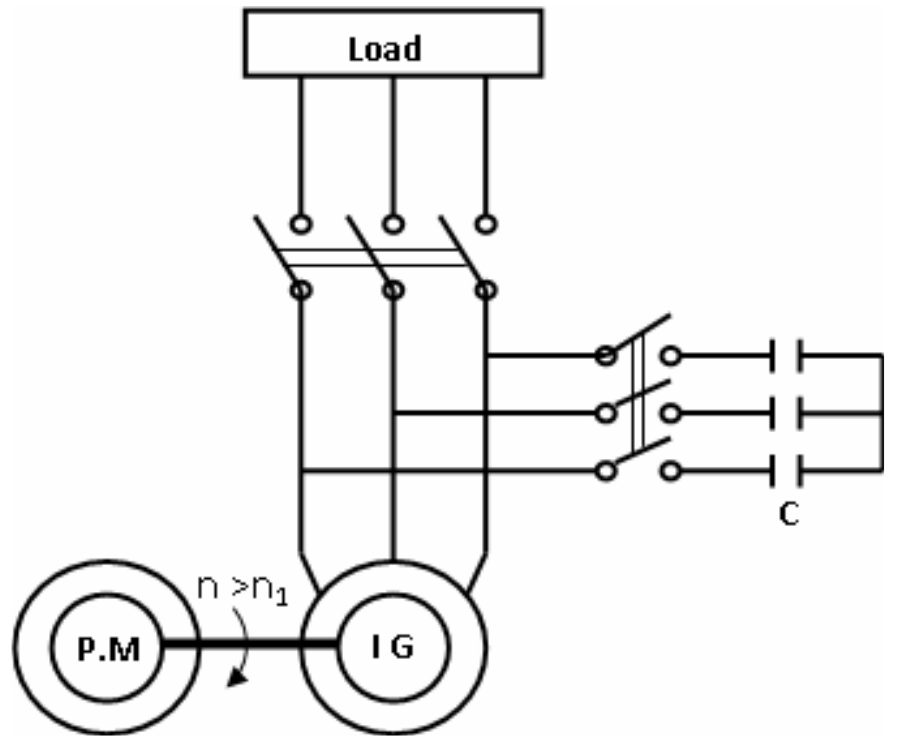

Figure 3. Connected Circuit for Self-Excitation Induction Generator[2].

Passing this current in stator winding increases magnetic flux in machine ,that causes increasing in electromotive force which generated in terminal of stator to $E$ that causes increasing the current which passes in capacitors to $I_{C}$ " that causes increasing magnetic flux, that causes increasing in electromotive force to $E^{\prime \prime}$ etc [14].

Self-excitation process continues as long as $\left(X_{1}+X_{O}\right) I_{C}>X_{C} I_{C}$, it stabilizes when the value of electromotive force which generated in generator to nominal value $E_{1}$ which is determined by the 
intersection point of the magnetization curve $E=f\left(I_{O}\right)$ with characteristics voltage amp for capacitor $U_{C}=I_{C} X_{C}$ as shown in figure (4).

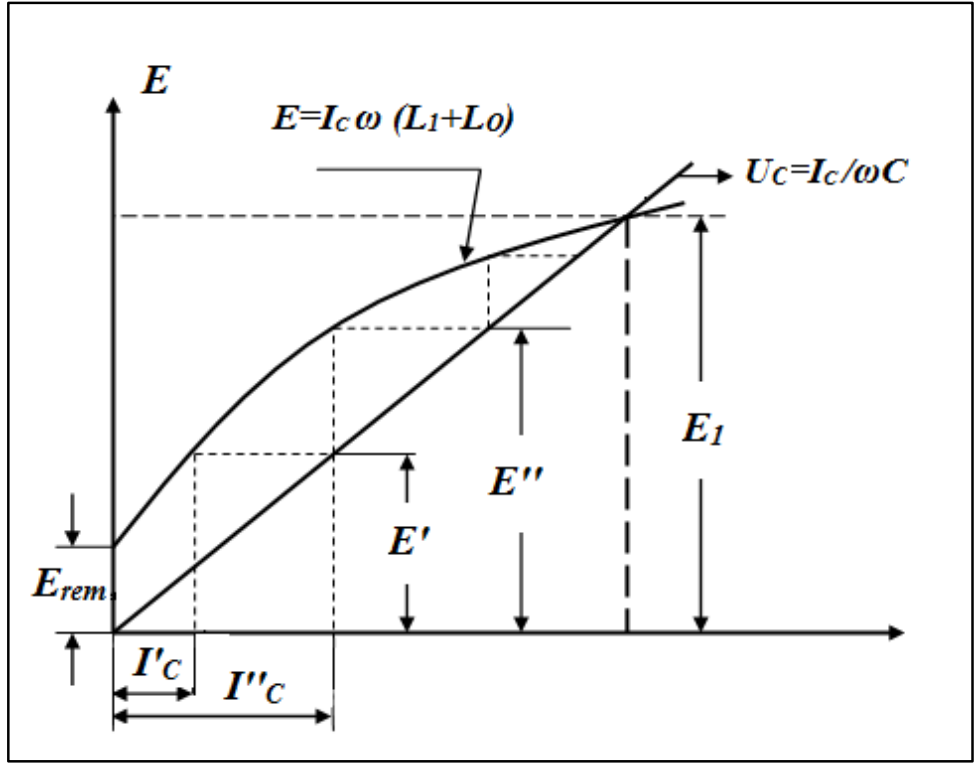

Figure 4. Self-Excitation in Induction Generator [6].

In this point voltage of generator equals to voltage of capacitor:

$$
U_{1}=U_{C}=\left(X_{1}+X_{O}\right) I_{C}=X_{C} I_{C}
$$

By equation (6) can find a relationship between the inducting factors $\left(L_{O}+L_{1}\right)$ for generator and capacity that required for excitation $C$ at a certain frequency $f=\frac{\omega}{2 \pi}$, as we find:

$$
\begin{gathered}
\left(L_{O}+L_{1}\right) \omega=\frac{1}{\omega \cdot C} \\
\left(L_{O}+L_{1}\right) C=\frac{1}{\omega^{2}}
\end{gathered}
$$

When $f=50 \mathrm{HZ}$ we find :

$$
\left(L_{O}+L_{1}\right) \cdot C \approx 10^{-5}
$$

We called capacity that match the characteristics of voltage amp (at a certain frequency) with the linear part for the characteristics of no load critical capacity $C_{c r}$, as it cannot be excite the generator at a certain speed unless capacity of capacitors was less than the critical capacity $C<C_{c r}$.

After excitation process, the generator are downloaded and then to maintain a fixed frequency $f=$ const. must change the rotational speed $n$ of the generator so that the value of $\operatorname{sip}(-s)$ matches with load that connected with it. All cases for working generator are Considering in this case by the equivalent circuit that shown in figure (5)

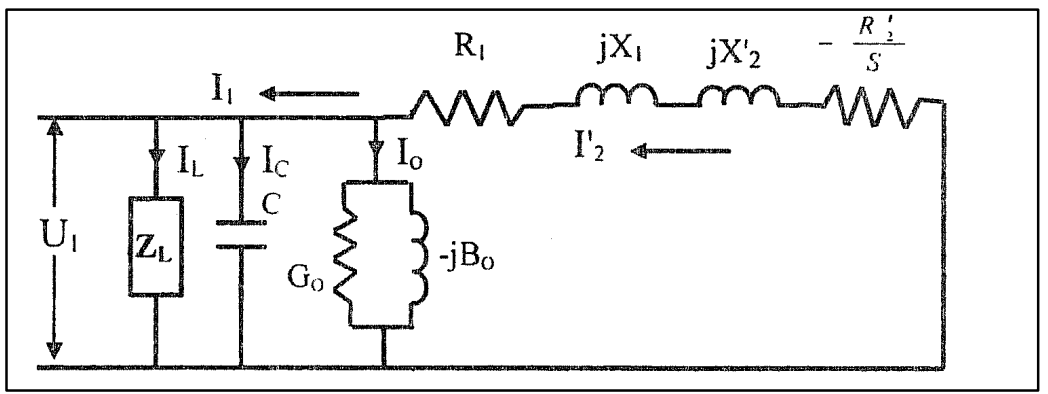




\section{Figure 5. Equivalent Electrical Circuit for Self - Excitation in Induction Generator[1].}

Capacity of Capacitors required for self-excitation in generator is calculated based on the value of reactive power $Q_{C}$ that provided by these capacitors, which calculates by the equation:

$$
\mathrm{Q}_{\mathrm{C}}=3 \mathrm{U}_{\mathrm{C}} \mathrm{I}_{\mathrm{C}} \sin \varphi_{\mathrm{C}}
$$

Since these capacitors are ideal so;

$$
\mathrm{Q}_{\mathrm{C}}=3 \mathrm{U}_{\mathrm{C}} \mathrm{I}_{\mathrm{C}}=3 \mathrm{U}_{\mathrm{C}} \omega \mathrm{CU}_{\mathrm{C}}=2 \mathrm{U}_{\mathrm{C}}{ }^{2} 2 \pi \mathrm{fC}=6 \pi \mathrm{fCU}_{\mathrm{C}}{ }^{2}
$$

In no load case, generator needs reactive power for self-excitation only, but in loading case, generator needs additional reactive power to provide the required of induction load that connected with it so we find[12]:

$$
\mathrm{Q}_{\mathrm{C}}=\mathrm{Q}_{\mathrm{G}}+\mathrm{Q}_{\mathrm{L}}=\mathrm{P}_{\mathrm{G}} \tan \varphi_{\mathrm{G}}+\mathrm{P}_{\mathrm{L}} \tan \varphi_{\mathrm{L}}
$$

$\mathrm{P}_{\mathrm{G}}$ :active power has provided by generators.

$\mathrm{P}_{\mathrm{L}}$ :active power has drawn by load.

$\varphi_{\mathrm{G}} \& \varphi_{\mathrm{L}}$ :phase angle between the current and the voltage in both of generator and load.

$\mathrm{U}_{\mathrm{C}}$ :voltage of capacitors.

When generator works at nominal load $P_{L}=P_{G n}=P_{n}$ this mean

$$
\begin{gathered}
\mathrm{Q}_{\mathrm{C}}=6 \pi f_{1} \mathrm{CU}_{\mathrm{C}}^{2}=\mathrm{P}_{\mathrm{n}}\left(\tan \varphi_{\mathrm{G}}+\tan \varphi_{\mathrm{L}}\right) \\
C=\frac{\mathrm{P}_{\mathrm{n}}\left(\tan \varphi_{\mathrm{G}}+\tan \varphi_{\mathrm{L}}\right)}{6 \pi f_{1} \mathrm{U}_{\mathrm{C}}^{2}} \cdot 10^{6} \quad(\mu F)
\end{gathered}
$$

This means that the capacity of the capacitors required can divided into two sections:

Constant capacity to excite generator when it works in no load case.

Variable capacity to provide the load by required reactive power.

Capacity of capacitors which required for excitation in no-load case is calculated by equation:

$$
C=K_{1} \frac{I_{n} \sqrt{3}}{6 \pi \mathrm{f} \mathrm{U}_{\mathrm{C}}} 10^{6} \quad(\mu F)
$$

Where :

$K_{1}$ : the ratio between no load current and nominal current for generator .

Notes from the equation (13) that the necessary capacity for excitation related to several factors, it is proportional to the power of generator $\mathrm{P}_{\mathrm{G}}$, and inversely with both the frequency $f$ (speed $n$ ) and a square of voltage $U^{2}[4]$, and proportional to $\tan \varphi_{G} \& \tan \varphi_{L}$ ( inversely with $\cos \varphi_{G} \& \cos \varphi_{L}$ ), this means that the power of capacitors that used with induction generators increases with increasing its power and fall down with falling down both voltage and frequency $[2][12]$. 


\section{EXPERMENTAL STUDY OF THE INDUCTION GENERATOR DRIVEN BY WIND TURBINE}

To achieve the experimental study of the induction generator driven by wind turbine, laboratory model is prepared figure (6) that consists of the following elements:

Dual speed (1430/940rpm) induction machine represents the induction generator be studied nominal values as follows:

$$
U_{n}=380[\mathrm{~V}] \quad P_{n}=900 / 300[\mathrm{~W}] \quad I_{n}=2.6 / 1.4[\mathrm{~A}]
$$

Mono speed(1430 rpm) induction Machine represents prime mover, the nominal values as follows:

$$
P_{n}=1100[W] \quad U_{n}=380 / 220[V] \quad I_{n}=3 / 5.5[A]
$$

Inverter (2 HP) to control the speed of prime mover .

Capacitors and measuring current, voltage and power, frequency and speed devices.

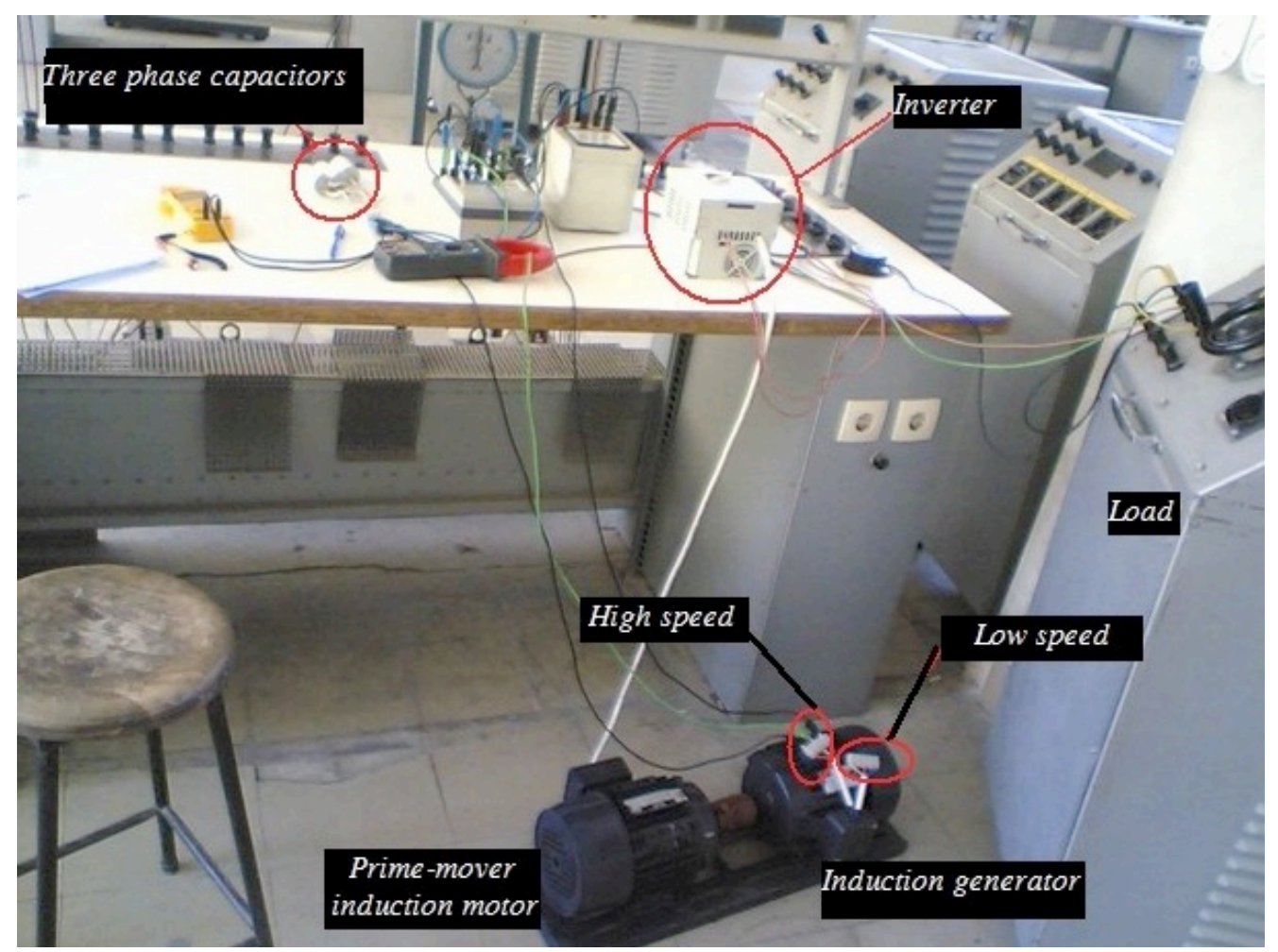

Figure 6. Laboratory Model That Used in Induction Generator Study.

\subsection{CONCLUSION DETERMINANTS OF EQUIVALENT CIRCUIT FOR THE INDUCTION GENERATOR FROM NO-LOAD \& SHORT CIRCUIY TEST:}

The goal of these tests is to get the equivalent circuit parameters for two-speed induction machine[4][9][13]. 


\subsubsection{NO-LOAD TEST:}

The two-speed induction machine is connected to AC variable source and is rotated to speed close to the speed synchronous and without load, after that, for each value of voltage variable between $35 \%$ and $120 \%$ of the nominal voltage of the machine, value of voltage $U_{1}$ that applied to the machine, phases currents $I_{A}, I_{B}, I_{C}$, active power that drawn from the grid $W_{I}+W_{I I}$ and rotation speed $n$ are recorded[1].

\subsubsection{SHORT CIRCUIT TEST:}

Short circuit test in induction machines tested when the rotor blocked with the application of low-voltage on the stator winding, here slip equals one, motor Stopped $n=0, s=1 \quad$ [1].

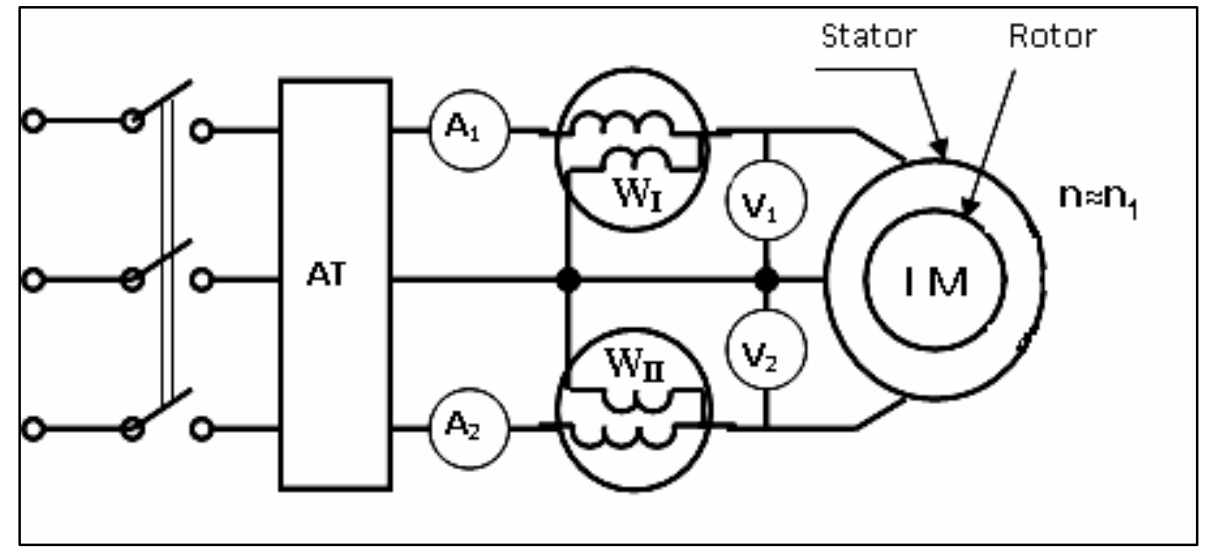

Figure 7. Connected Diagram for Induction Machine when No-load \&Short Circuit Test[1].

After we finished tests (that mentioned before) for the machine at high speed $n=1500 \mathrm{rpm}$ we get the following results:

Table 1. Results of No - load Test Where Speed is 1500 rpm.

\begin{tabular}{|c|c|c|c|c|c|c|}
\hline \multicolumn{7}{|c|}{ high speed } \\
\hline $\mathrm{U}_{\mathrm{o}}[\mathrm{v}]$ & $\mathrm{I}_{\mathrm{A}}[\mathrm{A}]$ & $\mathrm{I}_{\mathrm{B}}[\mathrm{A}]$ & $\mathrm{I}_{\mathrm{C}}[\mathrm{A}]$ & $\mathrm{W}_{1}[\mathrm{w}]$ & $\mathrm{W}_{2}[\mathrm{w}]$ & $\mathrm{n}[\mathrm{rpm}]$ \\
\hline 220 & 0.71 & 0.75 & 0.71 & 60 & 60 & 1490 \\
\hline 300 & 1 & 1 & 1 & 120 & 120 & 1495 \\
\hline 380 & 1.33 & 1.32 & 1.3 & 225 & 225 & 1496 \\
\hline
\end{tabular}

Table 2. Results of Short Circuit Test Where Speed is $1500 \mathrm{rpm}$.

\begin{tabular}{|c|c|c|c|c|c|}
\hline \multicolumn{5}{|c|}{ high speed } \\
\hline $\mathrm{U}_{\mathrm{SC}}[\mathrm{v}]$ & $\mathrm{I}_{\mathrm{A}}[\mathrm{A}]$ & $\mathrm{I}_{\mathrm{B}}[\mathrm{A}]$ & $\mathrm{I}_{\mathrm{C}}[\mathrm{A}]$ & $\mathrm{W}_{1}[\mathrm{w}]$ & $\mathrm{W}_{2}[\mathrm{w}]$ \\
\hline 30 & 0.9 & 0.92 & 0.91 & 15 & 15 \\
\hline
\end{tabular}




\begin{tabular}{|l|c|c|c|c|c|}
\hline 50 & 1.33 & 1.33 & 1.31 & 40 & 40 \\
\hline 70 & 1.5 & 1.56 & 1.54 & 70 & 70 \\
\hline
\end{tabular}

(At the same way we get the results for the low-speed )

Using mathematical equations and the results of the tests we calculate the determinants of the machine for each of speed (high - low)

Table 3. Determinants of Induction Machine for High-Speed $n=1500 \mathrm{rpm}$.

\begin{tabular}{|c|c|c|c|}
\hline \multicolumn{3}{|c|}{ high speed } \\
\hline$R_{1}=9.8[\Omega]$ & $\mathrm{R}_{2}^{\prime}=10.9[\Omega]$ & $X_{1}=8.16[\Omega]$ & $\dot{X}_{2}=9.11[\Omega]$ \\
\hline & $B_{0}=0.0051[\mathrm{~S}]$ & $G_{0}=0.003[\mathrm{~S}]$ & $\mathrm{Y}_{0}=0.00529[\mathrm{~S}]$ \\
\hline
\end{tabular}

Table 4. Determinants of Induction Machine for Low-Speed $n=1000 \mathrm{rpm}$.

\begin{tabular}{|l|c|c|c|}
\hline \multicolumn{3}{|c|}{ low speed } \\
\hline$R_{1}=35[\Omega]$ & $\mathrm{R}_{2}^{\prime}=16.3[\Omega]$ & $X_{1}=33.6[\Omega]$ & $\dot{X}_{2}=15.6[\Omega]$ \\
\hline & $B_{0}=0.0048[\mathrm{~S}]$ & $G_{0}=0.0018[\mathrm{~S}]$ & $\mathrm{Y}_{\mathrm{O}}=0.005[\mathrm{~S}]$ \\
\hline
\end{tabular}

\subsection{TESTS OF WORKING THE TWO-SPEED INDUCTION GENERATOR THAT WORKS INDEPENDLY OF THE GRID}

The goal of this practical tests is to determine the true of rotation speed when reach it , induction machine begins work as a generator, and determine capacity of capacitors that required to secure the nominal voltage at different rotation speeds Moreover, these tests are designed to get the external characteristics of the induction generator, in another meaning to get a curved relationship between change of terminal voltage of machine and the value of load that connected with it[4].

\subsubsection{TEST OF PHENOMENON OF SELF-EXCITATION FOR INDUCTION GENERATOR:}

During this test, two-speed induction machine is rotated by induction motor driven by inverter to obtain higher or lower than synchronous speed, and variable capacitors are connected to the terminal of the machine.

Changing of the rotational speed of the machine progresses at different values of the excitation capacitors until the appearance of voltage on the terminal of the generator.

When capacitors are separated from generator output voltage disappears completely, but when increase the capacity of the capacitors, voltage of generator terminal increases[11]. 
We follow a changing capacity of capacitors until the voltage of stator winding equals to the nominal voltage and measure the frequency of stator current, we find that it is proportional to the rotational speed $n$ of the rotor and fulfill the equation:

$$
f_{1}=\frac{p \cdot n_{1}}{60}
$$

When increase or decrease the capacity of capacitors with biding of the rotation speed is constant, followed by a proportional change in the value of the voltage without any change in the frequency value[13].

When Change the rotation speed with the biding of capacity of capacitors are constant, we note that the values of voltage and frequency change together by a proportional change rotation speed and the results of these tests are set out later[5].

\subsubsection{FREQUENCY CHARACTERSTICS TEST:}

The frequency characteristics of induction generators represents relationship between voltage and speed (or frequency) in the case of no load with the biding of capacity of capacitors are constant:

$$
U=f(n) \text { or } U=f(f) \text { when } C=\text { const. }
$$

Voltage of induction generator (in the case of no load) is proportional linearly with speed when magnetic flux is constant, but the magnetic flux related to capacitive current, which is proportional to the frequency, that is, when frequency or speed reduces, this capacitive current reduces too, leading to the bigger drop in the value of the voltage, and voltage disappears when speed becomes smaller than the critical value.

For obtaining to frequency characteristics for the induction generator follow these steps:

1- Calculate the capacity of capacitors required to connect with the generator( in the case of no-load) for getting a nominal voltage by using equation (14) we find:

$$
C=\frac{1.6 \times 2.6 \sqrt{3}}{2.6 \times 6 \pi .50 .380} \cdot 10^{6} \approx 8(\mu F)
$$

2 -Be sure that phenomenon of self-excitation occurred after that, voltage on terminal of the generator is measured.

3 -Begin to reduce speed on the stages(step by step) and score every time voltage values.

4-Replace capacity of capacitors by other that equal to $0.8 C_{n} \& 1.2 C_{n}$ and we repeat earlier stages.

5-Through the results, draw characteristics curves $U=f(n) \& U=f(f)$ for different capacity of capacitors $C=0.8 C_{n} \& C=1.2 C_{n} \& C=C_{n}$ [5].

- When we operate the generator at high speed $n=1500 \mathrm{rpm}$ we get the following results :

Table 5. Result of Frequency Characterstics at $n=1000 \mathrm{rpm} \& \mathrm{C}=12 \boldsymbol{\mu} \mathrm{F}$.

\begin{tabular}{|c|c|c|c|c|c|}
\hline \multicolumn{6}{|c|}{ high speed } \\
\hline \multicolumn{7}{|c|}{$C=12 \mu f$} \\
\hline $\mathrm{U}[\mathrm{V}]$ & 209 & 270 & 300 & 340 & 380 \\
\hline
\end{tabular}




\begin{tabular}{|c|c|c|c|c|c|}
$\mathrm{n}[\mathrm{rpm}]$ & $\mathbf{1 1 4 1}$ & 1226 & 1286 & 1380 & 1476 \\
\hline $\mathrm{I}_{\mathrm{G}}[\mathrm{A}]$ & 0.98 & 1.38 & 1.63 & 2 & 2.42 \\
\hline $\mathrm{f}[\mathrm{Hz}]$ & 37 & 40 & 41 & 44 & 47 \\
\hline
\end{tabular}

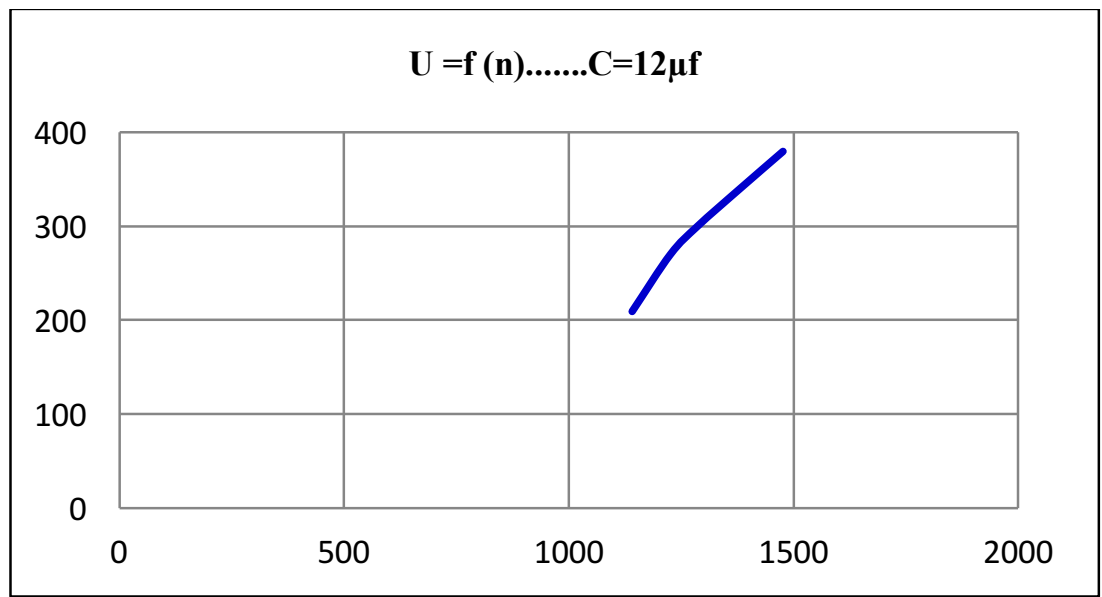

Figure 8. Shows $U=f(n)$ when $n=1500 r p m \& C=12 \mu F$.

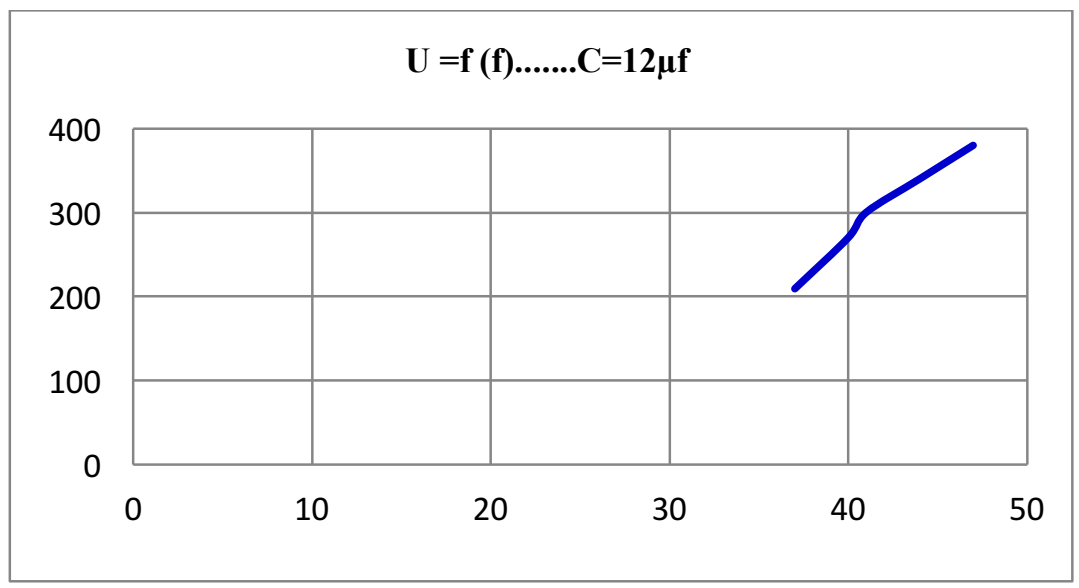

Figure 9. Shows $U=f(f)$ when $n=1500 r p m \& C=12 \mu F$.

From the previous curve \& table, we find that the excitation machine (when $C=12 \mu \mathrm{F}$ ) starts when $n=1141 \mathrm{rpm} \& U=209 \mathrm{~V}$, if speed increases, voltage and frequency will increase to reach the nominal voltage of the machine $380 \mathrm{~V}$ at speed $n=1476 \mathrm{rpm}$ and at frequency a lower than the nominal frequency $47 \mathrm{HZ}$.

Table 6. Result of Frequency Characterstics at $n=1500 \mathrm{rpm} \& \mathrm{C}=10 \mu \mathrm{F}$. 


\begin{tabular}{|c|c|c|c|c|c|}
\hline \multicolumn{7}{|c|}{ high speed } \\
\hline \multicolumn{7}{|c|}{$\mathrm{C}=10 \mu \mathrm{f}$} \\
\hline $\mathrm{U}[\mathrm{V}]$ & 207 & 270 & 300 & 340 & 380 \\
\hline $\mathrm{n}[\mathrm{rpm}]$ & $\mathbf{1 2 5 1}$ & 1330 & 1372 & 1448 & 1538 \\
\hline $\mathrm{I}_{\mathrm{G}}[\mathrm{A}]$ & 0.8 & 1.15 & 1.32 & 1.6 & 1.93 \\
\hline $\mathrm{f}[\mathrm{Hz}]$ & 40 & 43 & 44 & 48 & 50 \\
\hline
\end{tabular}

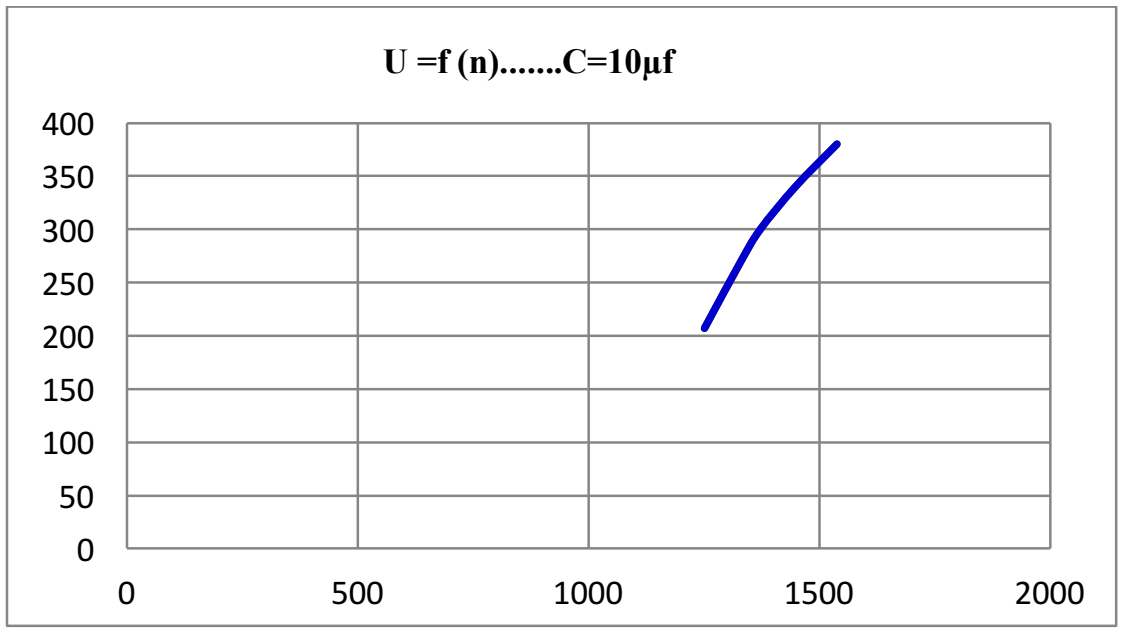

Figure 10. Shows $U=f(n)$ when $n=1500 r p m \& C=10 \mu F$.

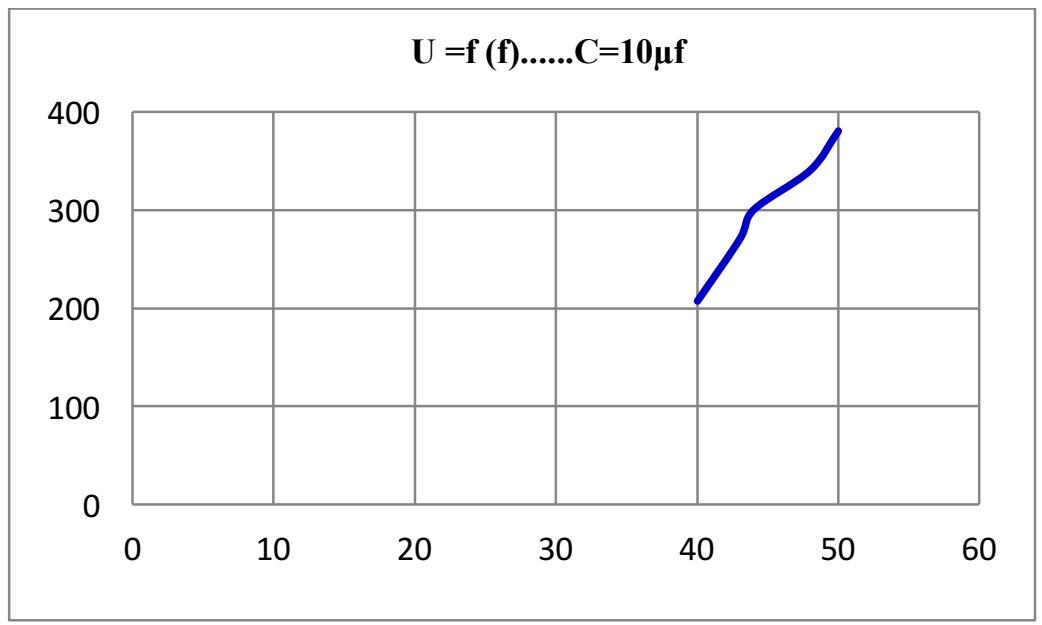

Figure 11. Shows $U=f(f)$ when $n=1500 r p m \& C=10 \mu F$.

From the previous curve $\&$ table, we find that the excitation machine ( when $C=10 \mu F$ ) starts when $n=1251 \mathrm{rpm} \& U=207 \mathrm{~V}$, if speed increases, voltage and frequency will increase to reach the nominal voltage of the machine $380 \mathrm{~V}$ at speed $n=1538 \mathrm{rpm}$ and at frequency a lower than the nominal frequency $50 \mathrm{HZ}$.

- When we operate the generator at low speed $n=1000 \mathrm{rpm}$ we get the following results : 
Table 7. Result of Frequency Characterstics at $n=1000 \mathrm{rpm} \& \mathrm{C}=10 \mu \mathrm{F}$.

\begin{tabular}{|c|c|c|c|c|c|}
\hline \multicolumn{7}{|c|}{ low speed } \\
\hline \multicolumn{7}{|c|}{$\mathrm{C}=10 \mu \mathrm{f}$} \\
\hline $\mathrm{U}[\mathrm{V}]$ & 338 & 350 & 360 & 373 & 380 \\
\hline $\mathrm{n}[\mathrm{rpm}]$ & 934 & 964 & 991 & 1023 & 1041 \\
\hline $\mathrm{I}_{\mathrm{G}}[\mathrm{A}]$ & 1.47 & 1.58 & 1.65 & 1.76 & 1.8 \\
\hline $\mathrm{f}[\mathrm{Hz}]$ & 42 & 43 & 44 & 45 & 46 \\
\hline
\end{tabular}

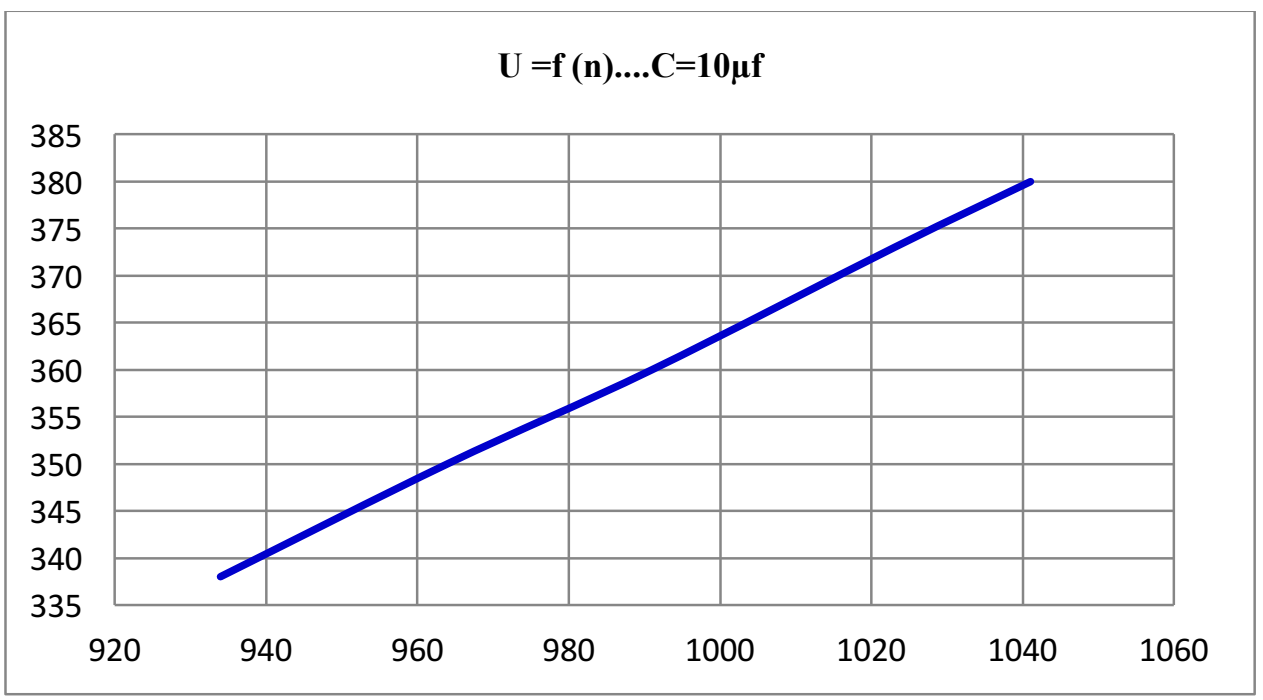

Figure 12. Shows $U=f(n)$ when $n=1000$ rpm \& $C=10 \mu F$.

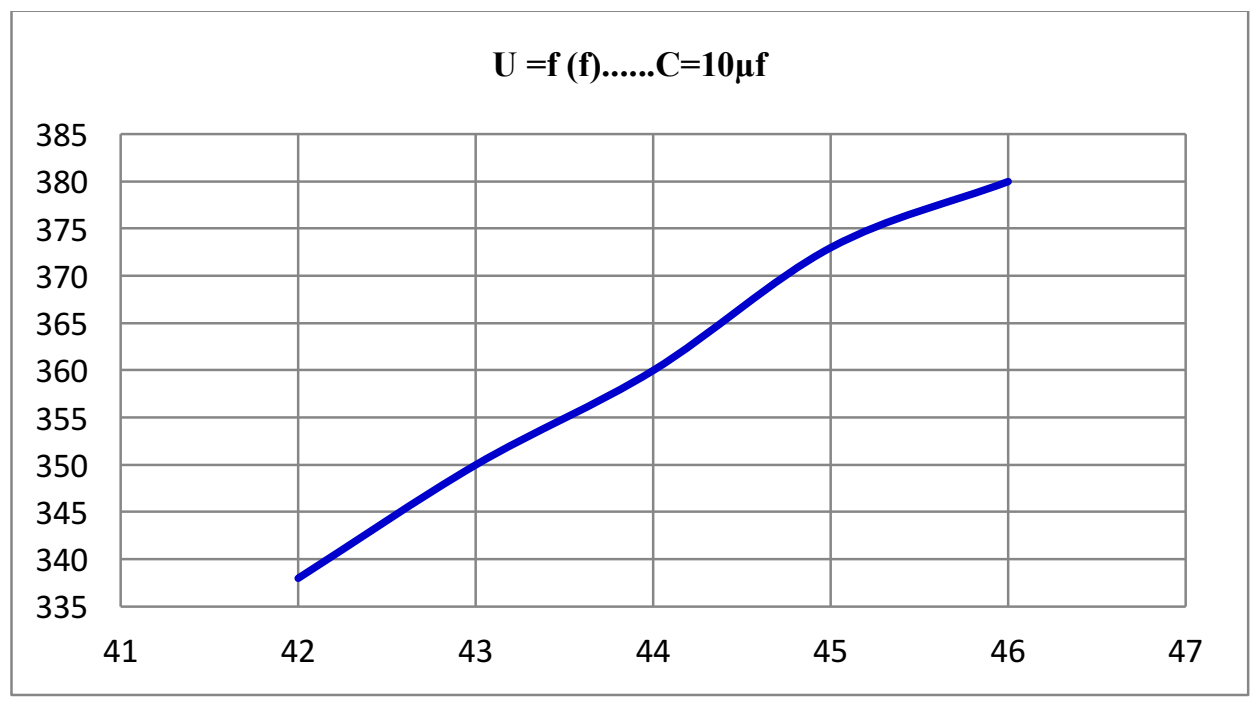

Figure 13. Shows $U=f(f)$ when $n=1000 r p m \& C=10 \mu F$. 
From the previous curve $\&$ table, we find that the excitation machine ( when $C=10 \mu F$ ) starts when $n=934 \mathrm{rpm} \& U=338 \mathrm{~V}$, if speed increases, voltage and frequency will increase to reach the nominal voltage of the machine $380 \mathrm{~V}$ at speed $n=1041 \mathrm{rpm}$ and at frequency a lower than the nominal frequency $46 \mathrm{HZ}$.

Table 8. Result of Frequency Characterstics at $n=1000 \mathrm{rpm} \& \mathrm{C}=8.5 \mu \mathrm{F}$.

\begin{tabular}{|c|c|c|c|c|}
\hline \multicolumn{5}{|c|}{ low speed } \\
\hline \multicolumn{5}{|c|}{$\mathrm{C}=8.5 \mu \mathrm{f}$} \\
\hline $\mathrm{U}[\mathrm{V}]$ & 341 & 364 & 370 & 380 \\
\hline $\mathrm{n}[\mathrm{rpm}]$ & $\mathbf{9 6 3}$ & 1005 & 1020 & 1041 \\
\hline $\mathrm{I}_{\mathrm{G}}[\mathrm{A}]$ & 1.33 & 1.49 & 1.53 & 1.6 \\
\hline $\mathrm{f}[\mathrm{Hz}]$ & 43 & 46 & 47 & 48 \\
\hline
\end{tabular}

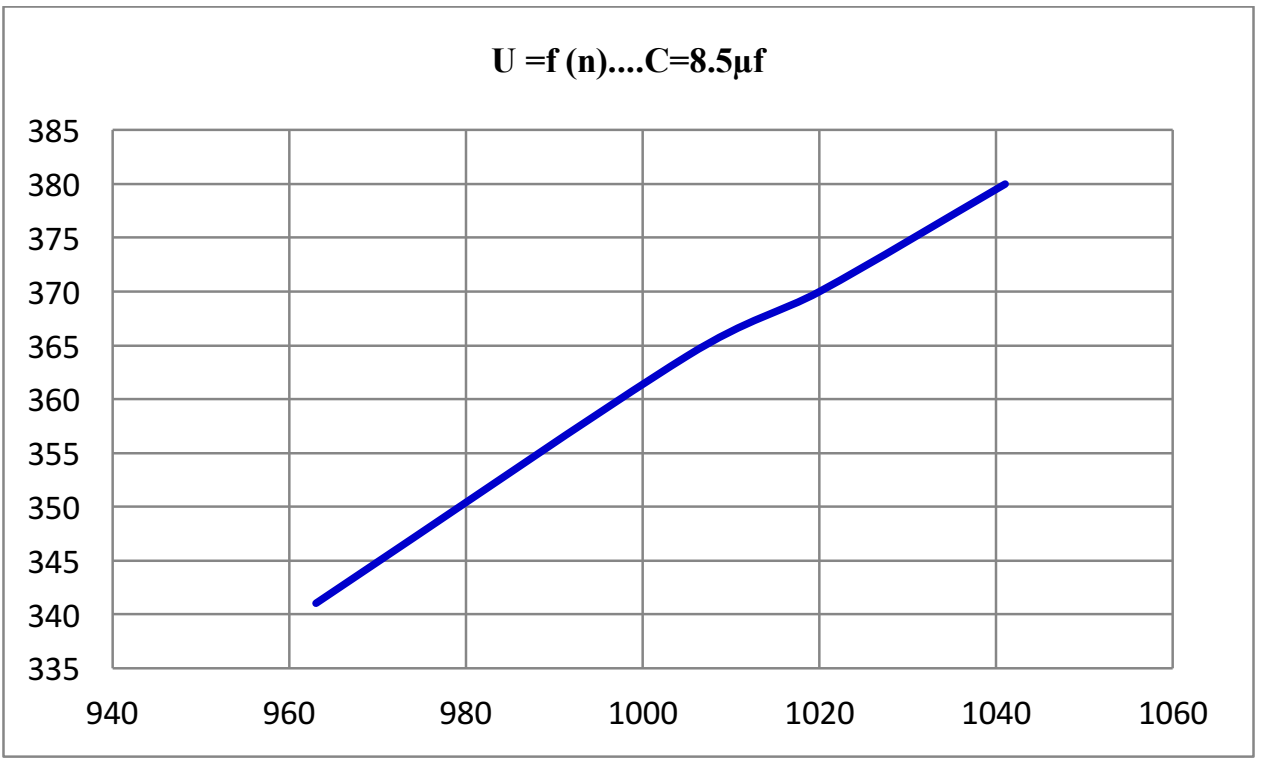

Figure 14. Shows $U=f(n)$ when $n=1000 r p m \& C=8.5 \mu F$. 


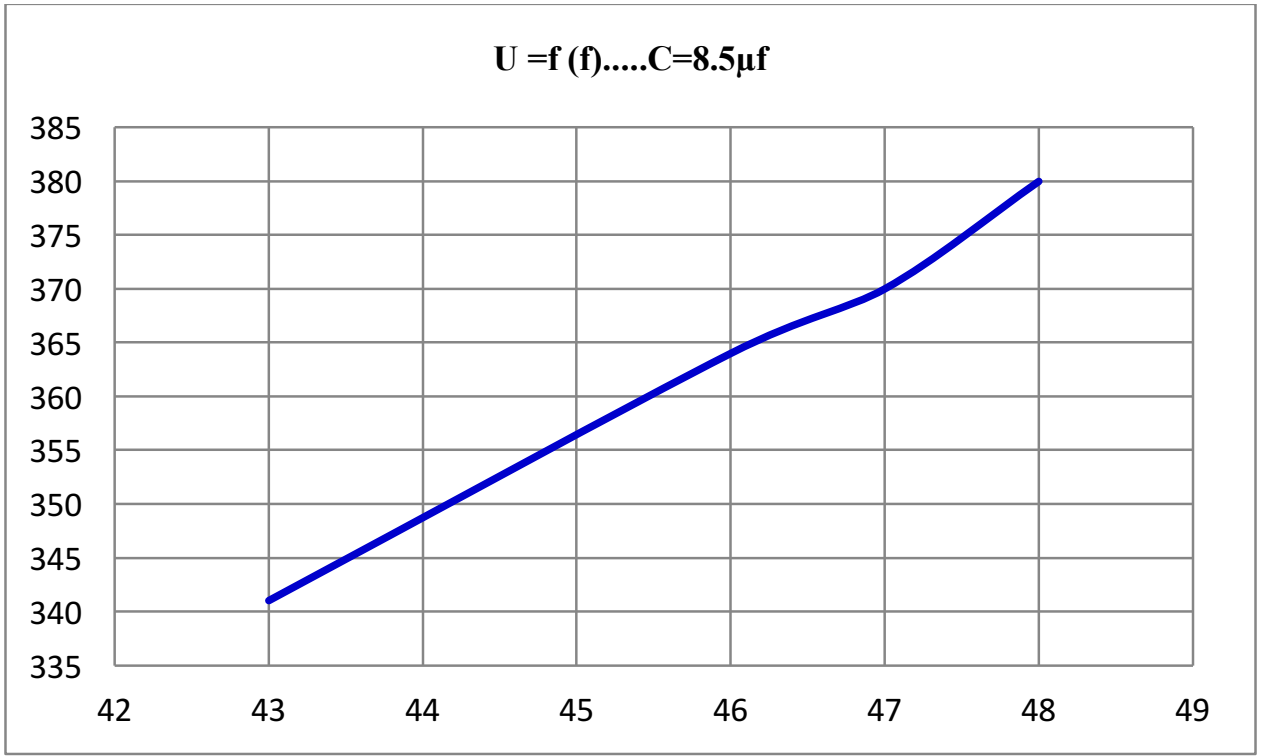

Figure 15. Shows $U=f(f)$ when $n=1000 r p m \& ~ C=8.5 \mu F$.

From the previous curve $\&$ table, we find that the excitation machine ( when $C=8.5 \mu F$ ) starts when $n=963 \mathrm{rpm} \& U=341 \mathrm{~V}$, if speed increases, voltage and frequency will increase to reach the nominal voltage of the machine $380 \mathrm{~V}$ at speed $n=1041 \mathrm{rpm}$ and at frequency a lower than the nominal frequency $48 \mathrm{HZ}$.

\section{3-2-3-STUDY OF EXTERNAL CHARACTERSTICS TEST:}

External characteristics for induction generators represents relationship between voltage on the terminal of the generator and the load current when capacity of capacitor $C$, frequency $f$ and load power factor $\cos \varphi_{L}$ are constant.

$$
U=f\left(I_{L}\right) \text { when } C=\text { const. }, f=\text { const. }, \cos \varphi_{L}=\text { const. }
$$

This test is fulfilled for purely ohmic load in order to previous same values for the capacitors.

Capacity of capacitors that must be linked with the generator( in case of loading) is Calculated by equation (13) to achieve self-excitation operation and to reach to the nominal voltage and nominal frequency

$$
\begin{aligned}
& C=\frac{P_{n}\left(\tan \varphi_{G}+\tan \varphi_{L}\right)}{6 \pi \cdot f \cdot U_{C}^{2}} \cdot 10^{6}(\mu F) \\
& C=\frac{900(1+0 \cdot 6)}{6 \pi \cdot 50 \cdot 380^{2}} \cdot 10^{6} \approx 11(\mu F)
\end{aligned}
$$

Generator is loaded by ohmic load, load is changed where frequency must been constant $f=f_{n}$ by control the speed, load power factor $\cos \varphi_{L}$ must been constant.

external characteristics curves $U=f\left(I_{L}\right)$ are Painted. 
in each case voltage drop is scored[5].

- When we operate the generator at high speed $n=1500 \mathrm{rpm}$ we get the following results :

Table 9. Result of External Characterstics at $n=1500 \mathrm{rpm} \& \mathrm{C}=12 \mu \mathrm{F}$.

\begin{tabular}{|c|c|c|c|c|c|c|}
\hline \multicolumn{7}{|c|}{ high speed } \\
\hline $\mathrm{I}_{\mathrm{L}}[\mathrm{A}]$ & 0.22 & 0.55 & 0.83 & 0.96 & 1.08 & 1.12 \\
\hline $\mathrm{I}_{\mathrm{G}}[\mathrm{A}]$ & 2.26 & 2.1 & 2 & 1.95 & 1.86 & 1.7 \\
\hline $\mathrm{U}[\mathrm{v}]$ & 360 & 330 & 300 & 280 & 250 & 220 \\
\hline
\end{tabular}

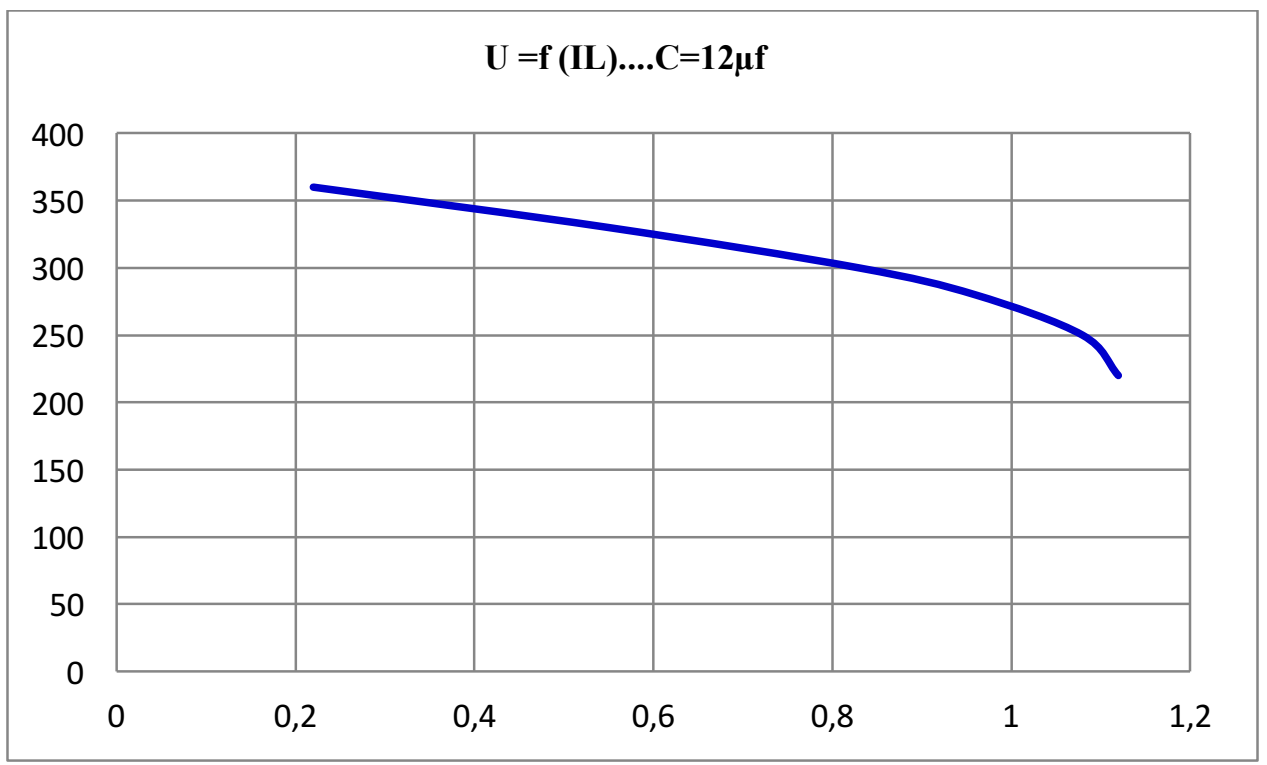

Figure 16. Shows $U=f\left(I_{L}\right)$ when $n=1500 r p m \& C=12 \mu F$.

Table 10. Result of External Characterstics at $n=1500 \mathrm{rpm} \& \mathrm{C}=10 \mu \mathrm{F}$.

\begin{tabular}{|c|c|c|c|c|c|c|c|}
\hline \multicolumn{1}{|c|}{ high speed } \\
\hline \multicolumn{1}{|c|}{$\mathrm{C}=10 \mu \mathrm{f}$} \\
\hline $\mathrm{I}_{\mathrm{L}}[\mathrm{A}]$ & 0.22 & 0.4 & 0.58 & 0.8 & 0.86 & 0.9 & 0.92 \\
\hline $\mathrm{I}_{\mathrm{G}}[\mathrm{A}]$ & 1.8 & 1.8 & 1.7 & 1.58 & 1.51 & 1.42 & 1.36 \\
\hline $\mathrm{U}[\mathrm{v}]$ & 360 & 340 & 320 & 280 & 250 & 220 & 200 \\
\hline
\end{tabular}


$U=f(I L) \ldots C=10 \mu f$

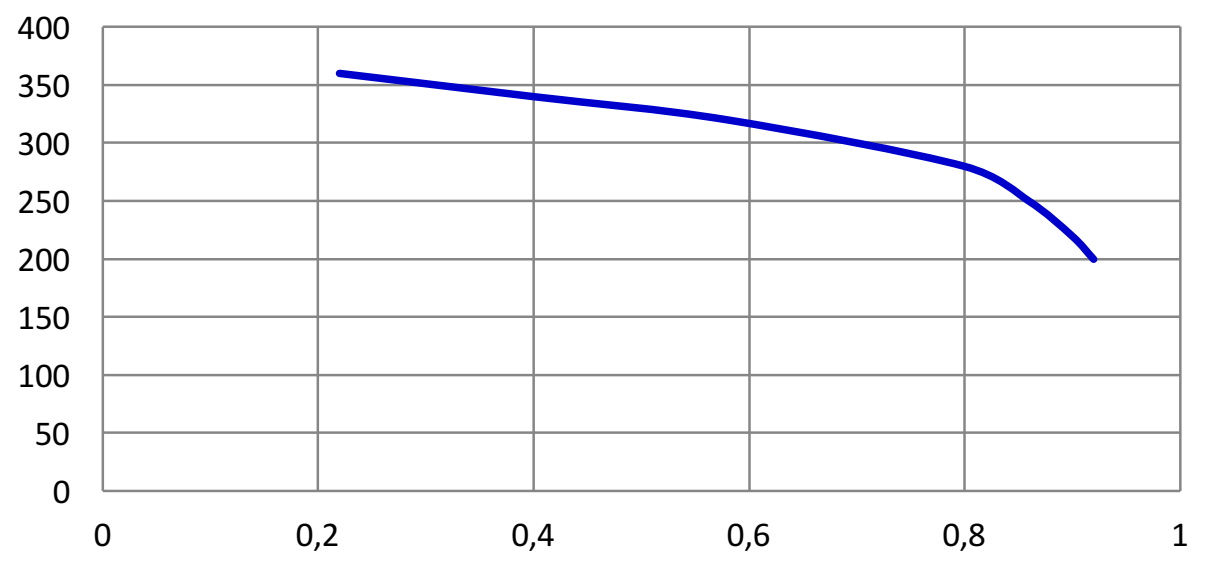

Figure 17. Shows $U=f\left(I_{L}\right)$ when $n=1500 \mathrm{rpm} \& C=10 \mu F$.

Table 11. Result of External Characterstics at $n=1500 \mathrm{rpm} \& \mathrm{C}=16 \mu \mathrm{F}$.

\begin{tabular}{|c|c|c|c|c|c|}
\hline \multicolumn{7}{|c|}{ high speed } \\
\hline \multicolumn{7}{|c|}{$\mathrm{C}=16 \mu \mathrm{f}$} \\
\hline $\mathrm{I}_{\mathrm{L}}[\mathrm{A}]$ & 0.22 & 0.62 & 0.95 & 1.12 & 1.25 \\
\hline $\mathrm{I}_{\mathrm{G}}[\mathrm{A}]$ & 2.8 & 2.6 & 2.4 & 2.27 & 2.25 \\
\hline $\mathrm{U}[\mathrm{v}]$ & 360 & 330 & 300 & 280 & 260 \\
\hline
\end{tabular}

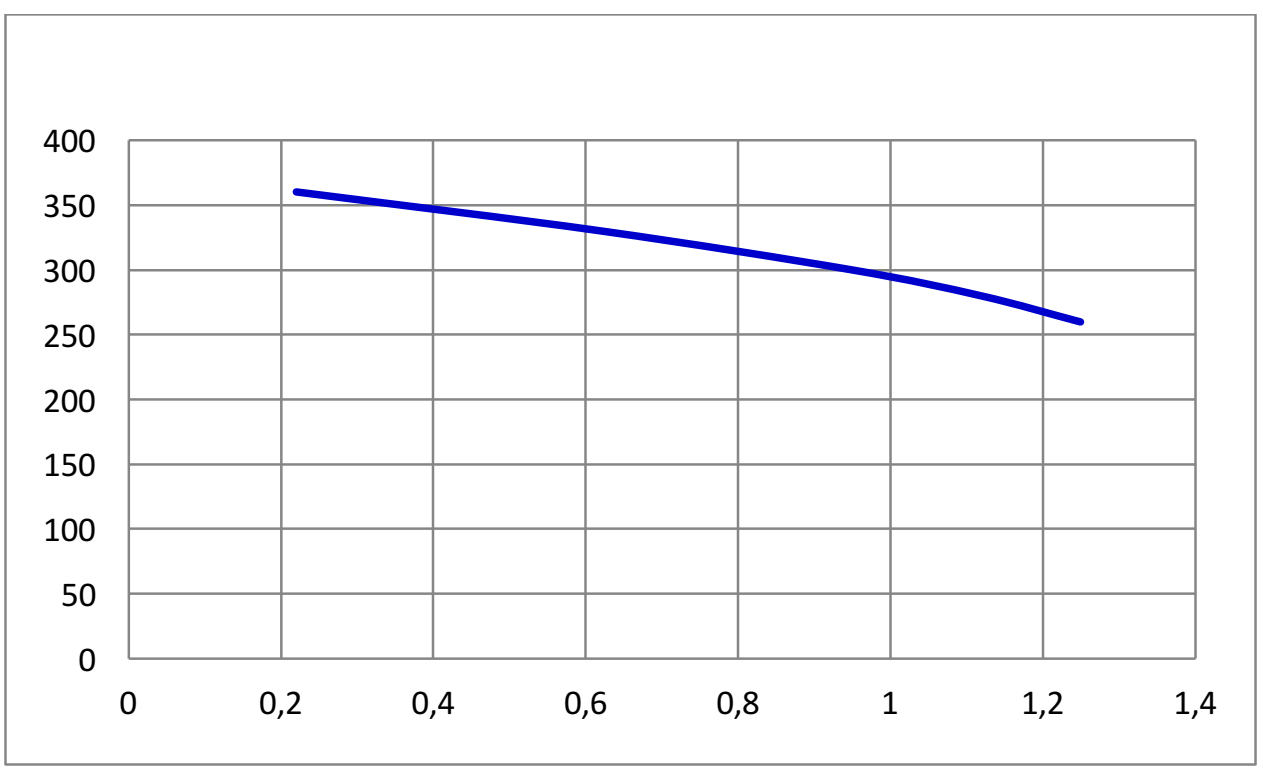


Figure 18. Shows $U=f\left(I_{L}\right)$ when $n=1500 r p m \& C=16 \mu F$.

- When we operate the generator at low speed $n=1000 \mathrm{rpm}$ we get the following results:

Table 12. Result of External Characterstics at n=1000 rpm \& $C=10 \mu F$.

\begin{tabular}{|c|c|c|c|c|c|c|c|}
\hline \multicolumn{7}{|c|}{ low speed } \\
\hline \multicolumn{7}{|c|}{$\mathrm{C}=10 \mu \mathrm{f}$} \\
\hline $\mathrm{I}_{\mathrm{L}}[\mathrm{A}]$ & 0.2 & 0.26 & 0.31 & 0.33 & 0.35 & 0.33 & 0.32 \\
\hline $\mathrm{I}_{\mathrm{G}}[\mathrm{A}]$ & 1.5 & 1.32 & 1.21 & 1.12 & 1.01 & 0.84 & 0.76 \\
\hline $\mathrm{U}[\mathrm{v}]$ & 316 & 290 & 250 & 230 & 200 & 165 & 150 \\
\hline
\end{tabular}

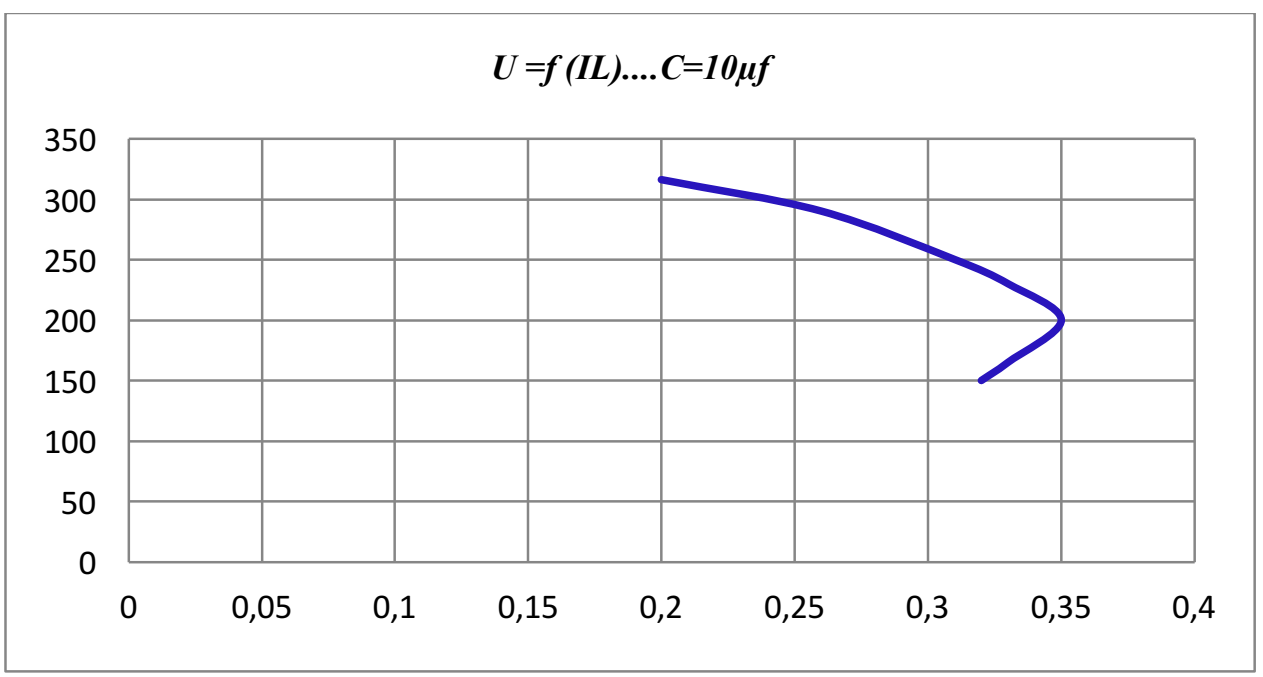

Figure 19. Shows $U=f\left(I_{L}\right)$ when $n=1000 r p m \& C=10 \mu F$.

Table 13. Result of External Characterstics at $n=1000 \mathrm{rpm} \& \mathrm{C}=8.5 \mu \mathrm{F}$.

\begin{tabular}{|c|c|c|c|c|c|c|c|}
\hline \multicolumn{1}{|c|}{ low speed } \\
\hline \multicolumn{1}{|c|}{$\mathrm{C}=8.5 \mu \mathrm{f}$} \\
\hline $\mathrm{I}_{\mathrm{L}}[\mathrm{A}]$ & 0.18 & 0.23 & 0.26 & 0.3 & 0.3 & 0.3 & 0.23 \\
\hline $\mathrm{I}_{\mathrm{G}}[\mathrm{A}]$ & 1.3 & 1.19 & 1.14 & 1.04 & 0.9 & 0.83 & 0.67 \\
\hline $\mathrm{U}[\mathrm{v}]$ & 306 & 280 & 266 & 240 & 200 & 180 & 150 \\
\hline
\end{tabular}




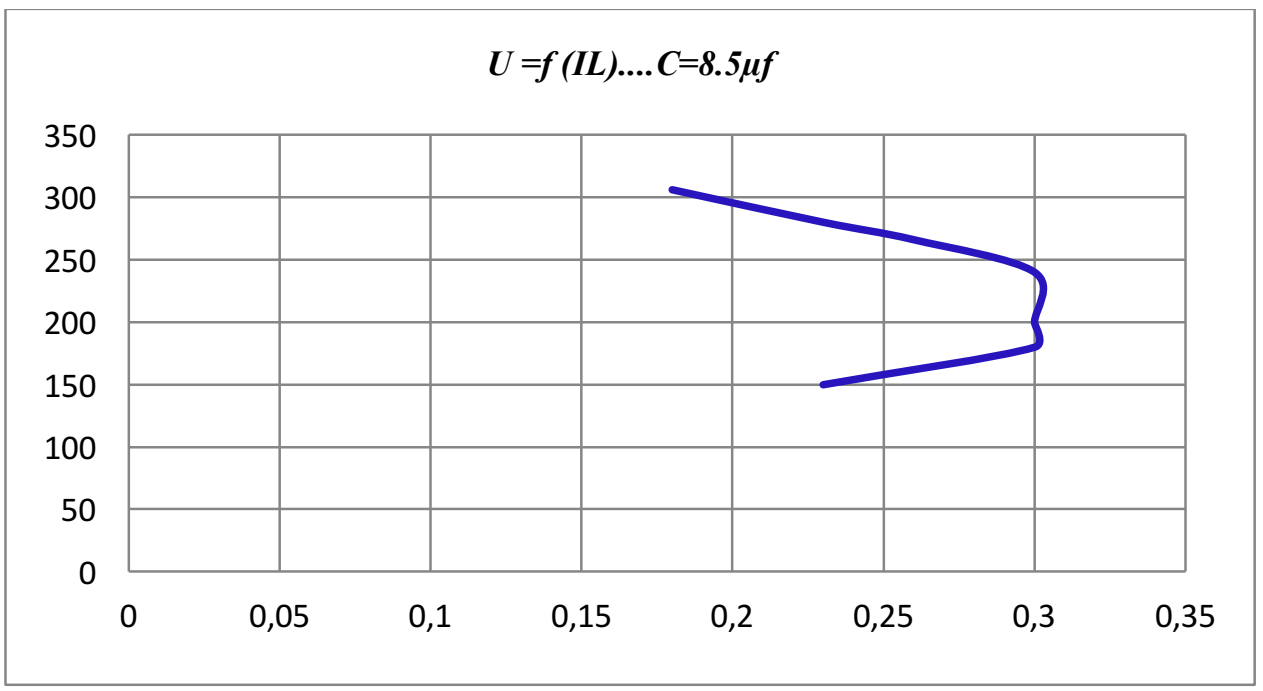

Figure 20. Shows $U=f\left(I_{L}\right)$ when $n=1500 \mathrm{rpm} \& C=8.5 \mu F$.

\section{CONCLUSION}

Through previous loading experiments for induction generator note that whenever the value of the capacity of capacitors is bigger, voltage drop is lower and characteristic becomes harder.

\section{RESULTS}

Through previous experiments for two -speed self-excitation induction generator driven by induction generator controlled by inverter, we found following:

The most important factors to ensure the quality of the performance of the machine as a generator are induction:

1-Residual magnetic flux in rotor of induction machine through a magnetic circuit.

2-precise calculation of capacity of capacitors which produce reactive power, in addition to the way of connecting for capacitors star or delta because of when capacitors are connected delta , capacity will be less than capacity when connecting is star about three times.

3-The machine needs specific rotation speed to start the excitation operation and then get an initial value of voltage and frequency where it appears unexpectedly.

4-When induction generator starts, you must work in the case of no load until voltage appears and set to the nominal value because of (that through experiments) if induction generator starts under load, voltage will not appear on the terminal of the induction machine.

\section{REFERENCES}

[1]Prof.Hagop Bogos , Prof.Ali Al-jazi, "Induction (Asynchronous) Machines",Damascus University, 2007. 
[2]Eng.Ziad Shihab, Prof. Abdulmotaleb Abou Seif, "Performance Study of Multispeed Induction Generators Used with Wind Turbines", Master Degree Thesis , Damascus University ,2011.

[3]Eng.Ziad Shihab, Prof. Abdulmotaleb Abou Seif, "Study for Performance Improvement for Double Speed Induction Generators Used With Independent Wind Turbines", Damascus University Journal Vol. (27) - No. (1) 2011.

[4]M. Ben Slimene, M. A. Khlifi, M. Ben Fredj, H. Rehaoulia, "Self Excitation in Dual Stator Winding Induction Generator for Renewable Energy Generation", IEEE ,The fifth International Renewable Energy Congress (IREC), Tunisia, March,2014.

[5]Eng.Omran Al-abed Al-khamis, Prof. Abdulmotaleb Abou Seif, Prof.Hagop Bogos, "Design Study for Decreasing Voltage Drop in Induction Generators Used with Wind Turbines", Master Degree Thesis, Damascus University ,2011.

[6] D.F.Warne,Newnes,"Electrical Power Engineer's", 2005.

[7] Malcolm Barnes,"Variable Speed Drives and Power Electronics".

[8] J.M.Elder, J.T.Boys, Prof.J.L.Woodward, "The process of self-excitation in induction generators", IEE PROC, Vol. 130, Pt. B, No. 2, March 1983, pp. 103-108

[9] M. Faisal Khan, M. Rizwan Khan, " Evaluation of Excitation Capacitance for a Single-Phase Two Winding Self Excited Induction Generator", IEEE , International Conference on Power Electronics, Drives and Energy Systems (PEDES) ,2014.

[10] Le Tang, Robert Zavadil, "Shunt Capacitor Failures due to Windfarm Induction Generator SelfExcitation Phenomenon", IEEE Transactions on Energy Conversion, Vol. 8, No. 3, September 1993, pp. 513-519

[11] S. Hazra, P.S. Sensarma, "Self-excitation and control of an induction generator in a stand-alone wind energy conversion system", IET Renew. Power Gener., Vol. 4, Iss. 4, 2010, pp. 383-393

[12] Jordan G. Trapp, Jocemar B. Parizzi, Felix A. Farret, Álvaro B. Serdotte, Adriano J. Longo, " STAND ALONE SELF-EXCITED INDUCTION GENERATOR WITH REDUCED EXCITATION CAPACITORS AT FIXED SPEED", IEEE ,2011, pp. 955-962

[13] Tarek Ahmed, Osamu Nor, Kazuya Matsuo, Yuji Shindo, Mutsuo Nakaoka, "Minimum Excitation Capacitance Requirements for Wind Turbine Coupled Stand-Alone Self-Excited Induction Generator with Voltage Regulation Based on SVC",IEICE/IEEE INTELEC'03, October,2003, pp. 396-403

[14] A.K. Swain, S. K. Senapati, " An Experimental Investigation of Self-Excitation in Stand-alone Induction Generator", IEEE , International Conference on Circuit, Power and Computing Technologies [ICCPCT],2014, pp. 245-249 